\title{
Mathematical simulation of forest fire front influence on wood- based building using one-dimensional model of heat transfer
}

\author{
Nikolay V Baranovskiy* and Aleksey Malinin \\ Tomsk Polytechnic University, School of Energy and Power Engineering, 634050, Lenin av., 30, Tomsk, Russian Federation
}

\begin{abstract}
The purpose of the present paper is to mathematical simulation of heat transfer in enclosures of wood-based building when exposed to thermal radiation from forest fire front. One-dimensional mathematical model is used. Mathematically, heat transfer in building enclosures is described by system of non-stationary equations of heat conduction with corresponding initial and boundary conditions. It is suggested to use several scenarios of forest fire impact. Temperature distribution on wall depth is obtained for different scenarios of forest fire impact on building enclosures.
\end{abstract}

\section{Introduction}

Forest fires are a catastrophic phenomena that causes ecological, economic and social damage [1]. The first is expressed in the amount of damaged or dead commercial timber, as well as in damage from the destruction or damage of rural settlements or industrial objects, which has taken place in the last decade [2]. Social damage is expressed in the number of people injured or dead in forest fires. In WUI territories, residential buildings can be involved in combustion processes [3-8]. The main impact of a forest fire is directed on the enclosing structures of a residential or industrial building [9-14]. The main mechanism of heat transfer in this case is radiant heat transfer [15]. Conducting large-scale experiments is either prohibited or difficult due to the inability to control all the parameters of the process [16]. The results of experimental and mathematical modeling $[17,18]$ can be applied in predicting forest fires in WUI territories [19-23]. Also, to solve this problem, the results obtained in the field of heat transfer [24], the spread of forest fires [25], geoinformation monitoring and remote sensing $[26,27]$ can be applied.

\section{Mathematical model}

As a physical model, a single-apartment wooden building was taken, located near a forest covered by fire. The front of the fire spreads at low speed in the absence of wind. The enclosing structures of this building are presented in the form of a two-layer plate. The first layer is cladding, the second is wood. Heat from the front of a forest fire is transmitted to the wall by thermal radiation. The main safety parameter of a wooden structure is the fact of ignition (or non-ignition) of the enclosing structure of the wooden building when a sufficient surface temperature is reached.

Following assumptions were made:

- Thermal conductivity mechanism in the enclosing structures;

- One-dimensional setting-up;

- The fire source is set parametrically;

- Thermophysical properties of building materials are independent of temperature;

- Neglect the presence of paint layer;

- Neglect evaporation of moisture from surface layers;

- Neglect wood pyrolysis.

Figure 1 shows the geometry of the solution domain.

A mathematical model is formulated, which is described by a system of equations:

$$
\begin{aligned}
& \rho_{1} c_{1} \frac{\partial T_{1}}{\partial t}=\lambda_{1} \frac{\partial^{2} T_{1}}{\partial x^{2}} . \\
& \rho_{2} c_{2} \frac{\partial T_{2}}{\partial t}=\lambda_{2} \frac{\partial^{2} T_{2}}{\partial x^{2}} .
\end{aligned}
$$

Initial conditions:

$$
\text { At } \mathrm{t}=0 \text { s. } \boldsymbol{T}_{\boldsymbol{i}}=\boldsymbol{T}_{\boldsymbol{i} \boldsymbol{0}} \text {. }
$$

Boundary conditions:

At the border, which is exposed to the front of a forest fire (at $x=0)$ :

$$
\begin{aligned}
& q_{f f}=-\lambda_{1} \frac{\partial T_{1}}{\partial x} . \\
& \text { For } \mathrm{x}=\mathrm{L}_{\mathrm{x} 1} . T_{1}=T_{2}, \\
& \lambda_{1} \frac{\partial T_{1}}{\partial x}=\lambda_{2} \frac{\partial T_{2}}{\partial x} .
\end{aligned}
$$

For $\boldsymbol{x}=\boldsymbol{L}_{\boldsymbol{x}}$.

$$
\alpha\left(T_{2}-T_{i n}\right)=-\lambda_{2} \frac{\partial T_{2}}{\partial x} .
$$

* Corresponding author: firedanger@yandex.ru 
Heat flux from forest fire:

The dependence of the value of the heat flux on the distance $l$ from the front of the forest fire to the surface of the building envelope [4]:

$q=326,37 e^{-0,2791 \cdot l}, k W / m^{2}$.

The dependence of the value of the heat flux on the flame height $h$ [4]:

$q=16,638 \cdot h+29,772, k W / m^{2}$.

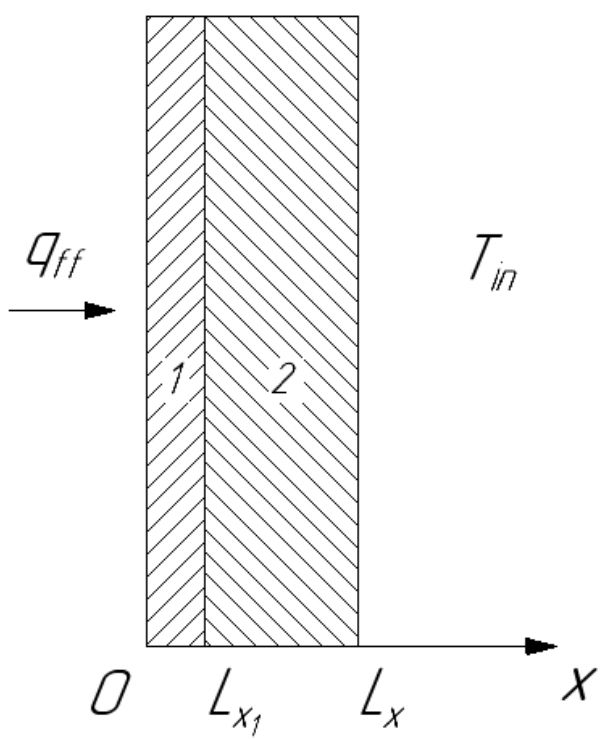

Fig. 1. Geometry of the solution area, where 1 cladding, 2 - wood

\section{Results and discussion}

The front of the forest fire begins its movement at a distance of $20 \mathrm{~m}$ from the enclosing structure of the wooden building. Wall cladding is made of plywood sheet $(0.05 \mathrm{~m}$ thickness). The second layer is made of pine wood. The fire front front speed was set at 1.5 $\mathrm{m} / \mathrm{min}$ and the flame height was set at $3 \mathrm{~m}$. See Table for computational scenarios.

Table 1. Initial data for numerical simulation

\begin{tabular}{cccccc}
\hline Calculation & $\begin{array}{c}\text { Exposure } \\
\text { Time, } \mathbf{s}\end{array}$ & $\begin{array}{c}\text { Heat } \\
\text { Flux, } \\
\mathbf{k W} / \mathbf{m} 2\end{array}$ & $\begin{array}{c}\text { Distance, } \\
\mathbf{m}\end{array}$ & Material & $\begin{array}{c}\text { Fire } \\
\text { Speed, } \\
\mathbf{m} / \mathbf{m i n}\end{array}$ \\
\hline $\mathbf{1}$ & 50 & 1,74 \\
$\mathbf{2}$ & 125 & 2,91 \\
\hline $\mathbf{3}$ & 200 & 4,89 \\
$\mathbf{4}$ & 275 & 8,21 \\
\hline $\mathbf{5}$ & 350 & 13,79 \\
\hline $\mathbf{6}$ & 425 & 23,14 & & & \\
\end{tabular}

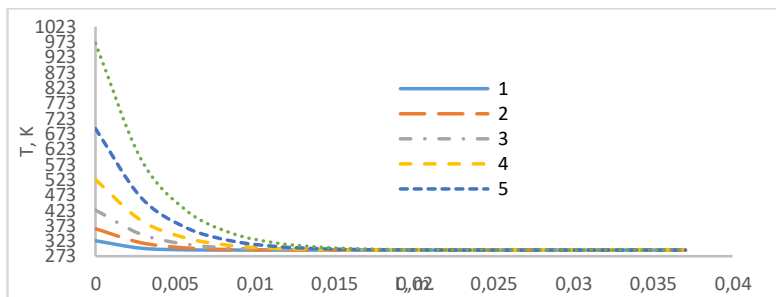

Fig. 2. Dependence of temperature distribution on exposure time

The front of the forest fire is located at a distance of 20 meters from the enclosing structure of a wooden building. The wall lining is made of plywood sheet with a thickness of 0.05 meters. The second layer is made of pine wood. The speed of the forest fire front increases from $1 \mathrm{~m} / \mathrm{min}$ to $3.5 \mathrm{~m} / \mathrm{min}$. Calculation time is $200 \mathrm{~s}$. See Table 2 for computational scenarios.

Table 2. Initial data for numerical simulation

\begin{tabular}{|c|c|c|c|c|c|}
\hline Coalculation & $\begin{array}{c}\text { Fire } \\
\text { Speed, } \\
\mathrm{m} / \mathrm{min}\end{array}$ & $\begin{array}{l}\text { Heat } \\
\text { Flux, } \\
\text { kW/m2 }\end{array}$ & $\begin{array}{c}\text { Distance, } \\
\mathbf{m}\end{array}$ & Material & $\begin{array}{r}\text { Exposure } \\
\text { Time, } s\end{array}$ \\
\hline 1 & 1 & 3,09 & \multirow{6}{*}{20} & \multirow{6}{*}{$\begin{array}{l}\text { Glued } \\
\text { Plywood }\end{array}$} & \multirow{6}{*}{200} \\
\hline 2 & 1,5 & 4,89 & & & \\
\hline 3 & 2 & 7,75 & & & \\
\hline 4 & 2,5 & 12,29 & & & \\
\hline 5 & 3 & 19,47 & & & \\
\hline 6 & 3,5 & 30,86 & & & \\
\hline
\end{tabular}

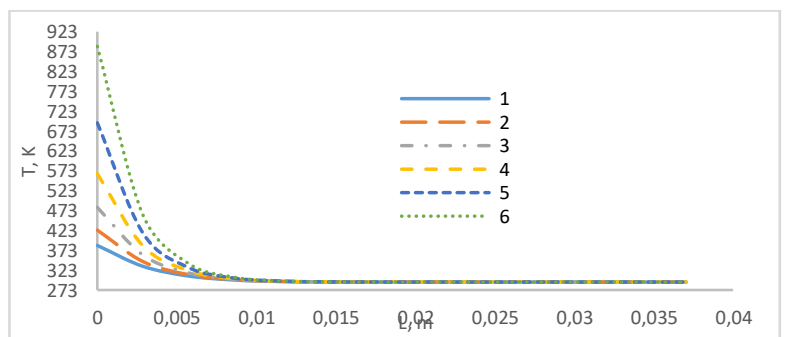

Fig. 3. Dependence of the temperature distribution on the velocity of the fire front

The front of the forest fire is at a distance of 2 meters from the enclosing structure of a wooden building. The wall lining is made of plywood sheet with a thickness of 0.05 meters. The second layer is made of pine wood. The height of the flame increases. Exposure time is $40 \mathrm{~s}$. See Table 3 for computational scenarios.

Table 3. Initial data for numerical simulation

\begin{tabular}{|c|c|c|c|c|c|}
\hline $\begin{array}{c}\text { Computational } \\
\text { Experiment }\end{array}$ & $\begin{array}{c}\text { Flame } \\
\text { Height, } \\
\text { m }\end{array}$ & $\begin{array}{c}\text { Heat } \\
\text { Flux, } \\
\mathbf{k W} / \mathbf{m}^{2}\end{array}$ & $\begin{array}{l}\text { Distance } \\
\text { from } \\
\text { Fire, } m\end{array}$ & Material & $\begin{array}{c}\text { Exposure } \\
\text { Time, } \mathbf{s} \\
\end{array}$ \\
\hline 1 & 0,1 & 31,4 & \multirow{6}{*}{ 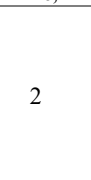 } & \multirow{6}{*}{$\begin{array}{l}\text { Glued } \\
\text { Plywood }\end{array}$} & \multirow{6}{*}{40} \\
\hline 2 & 0,2 & 33,1 & & & \\
\hline 3 & 0,3 & 34,8 & & & \\
\hline 4 & 0,4 & 36,4 & & & \\
\hline 5 & 0,5 & 38,1 & & & \\
\hline 6 & 0,6 & 39,8 & & & \\
\hline
\end{tabular}




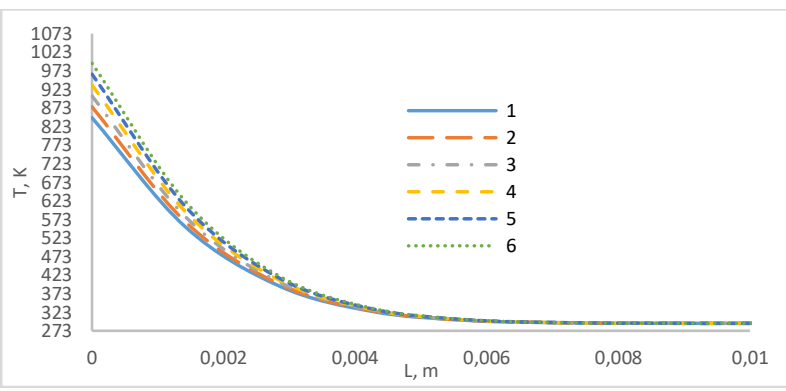

Fig. 4. Dependence of temperature distribution on flame height

The front of a forest fire begins its movement at various distances from 14 to 20 meters from the enclosing structure of a wooden building. The wall lining is made of plywood sheet with a thickness of 0.05 meters. The second layer is made of pine wood. The front movement speed was set at $1.5 \mathrm{~m} / \mathrm{min}$, the flame height was set at $3 \mathrm{~m}$, and the exposure time was set at 200 seconds. See Table 4 for computational scenarios.

Table 4. Initial data for numerical simulation

\begin{tabular}{llllll}
\hline $\begin{array}{l}\text { Computational } \\
\text { Experiment }\end{array}$ & $\begin{array}{l}\text { Flame } \\
\text { Height, } \\
\mathbf{m}\end{array}$ & $\begin{array}{l}\text { Heat } \\
\text { Flux, } \\
\mathbf{k W} / \mathbf{m}^{2}\end{array}$ & $\begin{array}{l}\text { Distance } \\
\text { from } \\
\text { Fire, } \mathbf{m}\end{array}$ & Material & $\begin{array}{l}\text { Exposure } \\
\text { Time, } \mathbf{s}\end{array}$ \\
\hline 1 & 14 & 26,1 & & & \\
\cline { 1 - 2 } 1 & 16 & \multicolumn{2}{c}{14,9} & $\begin{array}{l}\text { Glued } \\
\text { Plywood }\end{array}$ & 200 \\
\hline 3 & 18 & 8,54 & & & \\
\hline 4 & 20 & 4,89 & & &
\end{tabular}

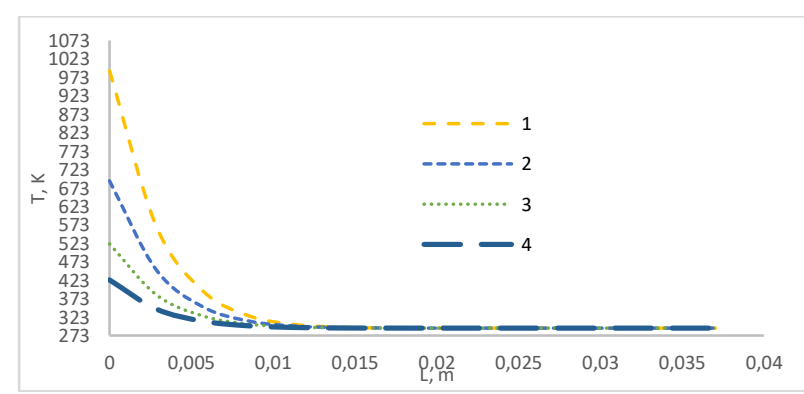

Fig. 5. Dependence of the temperature distribution on the distance between the front of a forest fire and the outer surface of the building envelope

The front of the forest fire begins its movement at a distance of 20 meters from the enclosing structure of the wooden building. The wall lining is 0.05 meters thick, the material is changing. The second layer is made of pine wood. The front movement speed was set at 1.5 $\mathrm{m} / \mathrm{min}$, the flame height was $3 \mathrm{~m}$, and the exposure time was $400 \mathrm{~s}$. See Table 5 for computational scenarios.
Table 5. Initial data for numerical simulation

\begin{tabular}{|c|c|c|c|c|c|}
\hline $\begin{array}{c}\text { Computational } \\
\text { Experiment }\end{array}$ & Material & $\begin{array}{l}\text { Heat } \\
\text { Flux, } \\
\mathbf{k W} / \mathbf{m}^{2}\end{array}$ & $\begin{array}{l}\text { Distance } \\
\text { from } \\
\text { Fire, } \mathbf{m}\end{array}$ & $\begin{array}{c}\text { Forest Fire } \\
\text { Velocity, m/min }\end{array}$ & $\begin{array}{c}\text { Exposure } \\
\text { Time, s }\end{array}$ \\
\hline 1 & $\begin{array}{c}\text { Glued } \\
\text { Plywood }\end{array}$ & 19,47 & \multirow{5}{*}{20} & \multirow{5}{*}{1,5} & \multirow{5}{*}{400} \\
\hline 2 & $\begin{array}{c}\text { Facing } \\
\text { Cardboard }\end{array}$ & 19,47 & & & \\
\hline 3 & $\begin{array}{c}\text { Fibreboard } \\
(1000)\end{array}$ & 19,47 & & & \\
\hline 4 & $\begin{array}{c}\text { Fibreboard } \\
(800)\end{array}$ & 19,47 & & & \\
\hline 5 & $\begin{array}{c}\text { Fibreboard } \\
(600)\end{array}$ & 19,47 & & & \\
\hline
\end{tabular}

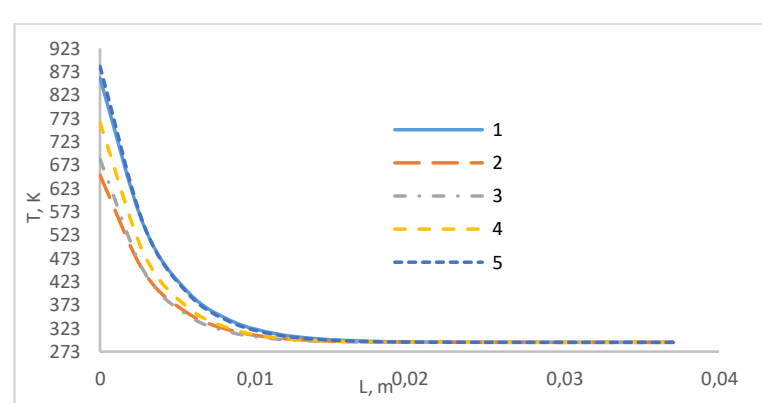

Fig. 6. Dependence of the temperature distribution on the material of the cladding of the enclosing structures

As a result, the following patterns were obtained:

According to the data obtained from Table 3, it can be concluded that, depending on the time of exposure, the depth of heating of the veneer made of glued plywood increased, but did not exceed $20 \mathrm{~mm}$. With increasing exposure time, the likelihood of thermal damage increases. At exposure times of more than 350 $\mathrm{s}$, thermal damage to plywood sheets is possible.

According Table 4, temperature distributions were obtained in a enclosing structure, which is subject to thermal effects from a forest fire front of different heights. The heat fluxes were quite large, since in [4] the heat flux values were obtained at a distance of 2 meters. In this case, at any flame height, thermal damage to the wall cladding is inevitable when the exposure time is more than $40 \mathrm{~s}$. An analysis of the obtained distributions showed that the flame height affects the temperature of the wall surface but has almost no effect on the depth of material.

According to Table 5, the dependence of the temperature distribution in the enclosing structure on the distance between the front of the forest fire and the surface of the building was studied. Based on the obtained distributions, it can be concluded that the distance affects the surface temperature of the enclosing structures but does not have a large effect on the material depth. A distance of less than $16 \mathrm{~m}$ with an exposure time of $200 \mathrm{~s}$ and a flame height of 3 meters is dangerous, since thermal damage to the outer layers is possible.

According to Table 6, the dependence of the temperature distribution inside the building on the speed of the front of a forest fire was studied. An analysis of the results showed that the surface temperature of the enclosing structure depends on the speed of movement and increases with increasing speed. So, in the conditions of a simulation scenario, when the exposure time is 200 with a dangerous speed, the front speed is 
more than $3 \mathrm{~m} / \mathrm{min}$. The speed of movement does not have a significant effect on the heating in the material depth.

According to Table 7, distributions were obtained for various cladding materials. Distributions were obtained at the same exposure time. According to the obtained distributions, it is clear that the thermal characteristics of the material affect the surface temperature. When comparing the distributions and thermophysical characteristics, the following dependences were obtained. With a decrease in thermal conductivity, the surface temperature increases. With a decrease in the density of the material, the surface temperature also increases. Thus, when using various cladding materials, the surface temperature was in the range from $651 \mathrm{~K}$ (Facing cardboard) to $884 \mathrm{~K}$ (fibreboards (600)).

An analysis of the results obtained according Table 8 showed that the material of the inner wall layer does not affect the temperature distribution inside the building, since the heating depth does not exceed the thickness of the lining. The thickness of the lining should be less than $20 \mathrm{~mm}$ in order for this factor to have any effect on the temperature distribution.

In this work, temperature distributions were obtained depending on the characteristics of the fire and the materials of the cladding panels and the materials of the inner layer of enclosing structures.

It can be seen from the obtained dependences that the temperature exceeding $900 \mathrm{~K}$ is reached in less than $500 \mathrm{~s}$. It can be concluded that in the event of a fire at a distance of less than $20 \mathrm{~m}$ from the surface of the building, there is little time to take actions to reduce social damage. To increase the possible response time, flame retardant treatment of the surfaces of the opposite forests is required. Moreover, it requires additional study of the composition and concentration of the flame retardants used.

Open placement of heat-insulating materials on the enclosing structure adjacent to the forest is unacceptable due to a significant increase in surface temperature relative to materials that are not heat insulators. Since the heating does not go further than $20 \mathrm{~mm}$, coating such surfaces with thin sheets of dense cladding will reduce the risk of rapid ignition.

The impact of a forest fire on a wooden building can be different, namely, radiant heat flux [15], direct flame exposure [17], particles of wood, vegetation and building materials heated to high temperatures [12]. Each of these factors requires separate attention in the context of mathematical modeling of heat transfer $[18,20,24]$. This paper considers the scenario of the effect of a radiant heat flux [15] on the enclosing structures of a wooden building. It should also be noted that the influence of a forest fire with a different speed of fire front propagation over forest fuels is considered, which is also due to different wind speeds [3]. It should be understood that the problem of forest fires is complex and one should take into account not only the characteristics of the spread of a forest fire [25], but also the properties of building materials [9-11,13]. Therefore, in this work, mathematical modeling was carried out taking into account specific building materials used in the Russian Federation.

One more assumption made in the considered mathematical model should be discussed. In this work, the process of pyrolysis of wood and wood-glued materials [14] is ignored. Initially, one might think that an important physicochemical process was not taken into account in mathematical modeling of the effect of a radiant heat flux on the enclosing structures of a wooden building. However, inert heating is the first and decisive stage in the combustion of wood-based materials. Moisture evaporation and the subsequent thermal decomposition of dry organic matter of wood is determined precisely by the intensity and extent of heating in the sample. Therefore, it is important to assess the increase and distribution of temperature across the thickness of the cladding material during the period of exposure by a forest fire. To determine the ignition conditions for each type of material, critical parameters can be determined: the temperature of the ignition surface and the heat flux to this surface. Therefore, the ignition conditions for specific cladding materials of a wooden building can be determined with satisfactory accuracy without taking into account the pyrolysis of wood-glued materials.

It should be noted that the problem of forest fires in WUI territories is relevant for various states with forested territories [2, 4-7, 19, 21]. Moreover, a number of researchers note $[16,22,23]$ that over time the area of WUI territories will increase. Consequently, the scale of catastrophic forest fires in WUI territories will increase. Therefore, it is necessary to take preventive measures, including the design and development of WUI territories [8, 27].

The creation of a deterministic model of the effect of thermal radiation from the front of a forest fire creates objective prerequisites for the implementation of information computer systems in the fire safety predicting systems of settlements located near forests in the WUI $[1,21-23,26]$.

\section{Conclusion}

As shown above, the problem of forest fires in WUI territories has been relevant recently. This is due to a number of reasons, including the availability of forested areas to residents of cities and rural settlements, an increase in anthropogenic load on forested areas, as well as climatic changes. The increase in the number of forest fires in the WUI territories and the increase in the burned area requires the development of information and computing systems for monitoring and assessing the fire safety of settlements during the fire season. It should be noted that the development of deterministic mathematical models of heat transfer in the building enclosures together with probabilistic criteria can provide a solution to this problem.

This work was supported by the Russian Foundation for Basic Researches. Project N 17-29-05093. 


\section{References}

1. N.V. Baranovskiy, G.V. Kuznetsov, Forest fire occurrences and ecological impact prediction: monograph. Novosibirsk: Publishing House of the Siberian Branch of the Russian Academy of Science, (2017)

2. W.E. Mell, S.L. Manzello, A. Maranghides, D. Butry, R.G. Rehm, International Journal of Wildland Fire, 19:238-251 (2010).

3. R.G. Rehm, The effects of winds from burning structures on ground-fire propagation at the wildland-urban interface. National Institute of Standards and Technology. Report GCR 06-892. 1 - 31. (Gaithersburg, MD)

4. E. Ronchi, S.M.V. Gwynne, G. Rein, P. Intini, Safety Science, 118:868-880 (2019).

5. S. Vaiciulyte, E.R. Galea, A. Veeraswamy, L.M. Hulse, International Journal of Disaster Risk Reduction, 40, 101272 (2019).

6. R. Sapiains, A.M. Ugarte, P. Aldunce, G. Marchant, J.A. Romero, M.E. González, V. Inostroza-Lazo, Sustainability, 2, 4298 (2020), doi: $10.3390 /$ su12104298

7. E. Pastor, J.A. Munoz, D. Caballero, A. Agueda, F. Dalmau, E. Flanas, Fire Technology, 56:18311851 (2020).

8. P. Intini, E. Ronchi, S. Gwynne, N. Benichou, Fire Technology, 56:1853-1883 (2020).

9. D.P. Kasymov, M.V. Agafontsev, V.V. Perminov, Chechekov, A. Yu, IOP Conf. Series: Journal of Physics: Conf. Series. 1129, 012017 (2018).

10. J.S. Kristensen, G. Jomaas, Fire Technology, 54: 1807-1828 (2018).

11. V.P. Zima, D.P. Kasymov, Journal of Engineering Physics and Thermophysics, 91,4:913-917(2018).

12. S. Suzuki, S.L. Manzello, International journal of heat and mass transfer, 130: 135-140 (2019).

13. L.M. Osvaldova, P. Kadlicova, J. Rychly, Coatings, $\quad 10, \quad 527 \quad 2020$. doi:10.3390/coatings 10060527

14. F. Richter, G. Rein, Combustion and Flame, 216:316-325 (2020).

15. E.N. Valendik, I.V. Kosov, Siberian Journal of Ecology. 4, 517-523(2008).

16. J.D. Cohen, Journal of Forestry, 98:15 - 21 (2000).

17. P.N. Goman, The Dynamics of Surface Forest Fire and Forest Fuel Ignition Under the Heat Radiation From the Fire Line. In: N.V. Baranovskiy, (Eds.), Predicting, Monitoring, and Assessing Forest Fire Dangers and Risks (1-47) (2020). IGI Global. http://doi:10.4018/978-1-7998-1867-0.ch001

18. V.A. Perminov, Mathematical Modeling of Steppe Fires. In: N.V. Baranovskiy, (Eds.), Predicting, Monitoring, and Assessing Forest Fire Dangers and Risks (48-62). IGI Global (2020). http://doi:10.4018/978-1-7998-1867-0.ch002

19. A. Badia, M. Pallares-Barbera, N. Valldeperas, M. Gisbert, Science of the Total Environment, 673:184-196 (2019).

20. N. Baranovskiy, A. Malinin, Sustainability, 12, 5475 (2020).
21. R.B. Hammer, V.C. Radeloff, J.S. Fried, J.S. Stewart, S.S. Holcomb, A.J. McKeefry, Ecological Applications 15:799-805 (2005). doi:10.1890/041413.

22. D.J. Nowak, J.T. Walton, Journal of Forestry 103:383-389 (2005).

23. R.B. Hammer, V.C. Radeloff, J.S. Fried, J.S Stewart, International Journal of Wildland Fire 16: 255-265 (2007). doi:10.1071/WF06063.

24. Baranovskiy N., Demikhova A. Safety 2019, 5, 56.

25. P. Andrews, C. Bevins, Update and expansion of the BEHAVE fire behaviour prediction systems. In 'Proceeding of the 14th Conference on Forest Fire Research and 14th Conference on Fire and Forest Meteorology ', 16-20 november 1998, Luso , Coimbra, Portugal. (Ed. Dx Viegas) 1, 733-740. (ADAI, University of Coimbra) (1998).

26. E.P. Yankovich, K.S. Yankovich, Classification of Territory on Forest Fire Danger Level Using GIS and Remote Sensing. In Baranovskiy, N.V. (Ed.), Predicting, Monitoring, and Assessing Forest Fire Dangers and Risks (258-267). IGI Global (2020). http://doi:10.4018/978-1-7998-1867-0.ch011

27. K. Lowell, R. Shamir, A. Siqueira, J. White, A. O'Connor, G. Butcher, M. Garvey, M. Niven, International Journal of Wildland Fire 18:10101020 (2009). doi:10.1071/WF08077. 